\title{
FEG-EPMA of Solid State Redox Sensors - the Effect of Secondary Fluorescence on Analytical Precision
}

\author{
Jon Wade ${ }^{1}$, Ben Buse ${ }^{2}$, Stuart Kearns ${ }^{2}$ \\ ${ }^{1}$ Dept of Earth Sciences, University of Oxford, South Parks Road, Oxford. OX1 3AN \\ ${ }^{2}$ School of Earth Sciences, University of Bristol, Queens Road, Bristol. BS8 1RJ
}

High-pressure oxygen fugacity ('redox') sensors are widely used to make estimates of the effective concentration of oxygen in experimental petrology. They typically rely on iron either diffusing into a nominally iron free mineral (e.g. iron into magnesiowüstite [1]) or iron alloying with a noble metal[2, 3 ]. In both cases the iron content of the sensor material should reflect the prevailing oxygen fugacity of the experiment, assuming all the phases are in local chemical equilibrium. The composition of the sensor is typically controlled by diffusion of iron into a crystalline (e.g. $\mathrm{MgO}$ ) or solid metallic material, hence for accurate estimation of the experimental redox conditions, analysis of the sensor's iron content is made as close as possible to the sensor/experiment boundary.

The preferred technique for such measurements - one with both the analytical spatial and chemical resolution is that of wavelength dispersive EPMA. The field emission gun (FEG) variant of the instrument allows for ultimate resolution. However, the accuracy of the redox sensor is invariably limited by elemental diffusion - especially true of the iron in magnesiowüstite type sensors - analytical problems are also compounded by the fact that the sensor's iron content is often lower than that of the experimental melt it is in contact with. Hence there exists the potential for secondary X-ray fluorescence (SF), from higher energy characteristic X-rays and/or X-ry continuum[4], to introduce errors into the measurement of a key experimental parameter (oxygen fugacity). Fortunately, SF contributions can be relatively easily assessed and analyses corrected, especially with the advent of the PENELOPE and FANAL[5] codes contained within the GUI of CalcZAF (Ref) which contains pre-built geometry files for a binary, user defined, couple.

In the case of the magnesiowüstite-Fe sensor, the iron concentrations may range from $<150 \mathrm{ppm}$ to a few wt\%, with lower iron concentrations reflecting more chemically reducing conditions (figure 1). Hence, for good analytical precision EPMA is typically carried out at accelerating voltages of $10 \mathrm{kV}$, but, interestingly, the simulations show that there is a maxima in the secondary fluorescence contribution from the X-ray continuum between 10 and $15 \mathrm{kV}$, such that lowering the accelerating voltage does not necessarily reduce the SF contribution. Here we explore the contribution of SF on two commonly used redox sensors (magnesiowüstite- and AuPd-Fe) both by modelling and analysis, and show that for the case of the magnesiowüstite sensor this maxima is real (figure 1A). We also explore the role that detector geometry with respect to the phase boundary may have upon the analysis and calculate the degree to which this affects analytical uncertainty.

[1] Srecec, I., et al., Physics And Chemistry Of Minerals,. 14 (1987) p. 492-498.

[2] Balta, J.B., J.R. Beckett, and P.D. Asimow, American Mineralogist,. 96 (2011) p.1467-1474.

[3] Barr, J.A. and T.L. Grove, Contributions to Mineralogy and Petrology, 160 (2010) p. 631-643. 
[4] Dalton, J.A. and S.J. Lane, American Mineralogist, 81 (1996) p. 194-201.

[5] Donovan, J.J., H.A. Lowers, and B.G. Rusk, American Mineralogist,. 96 (2011) p.274-282.

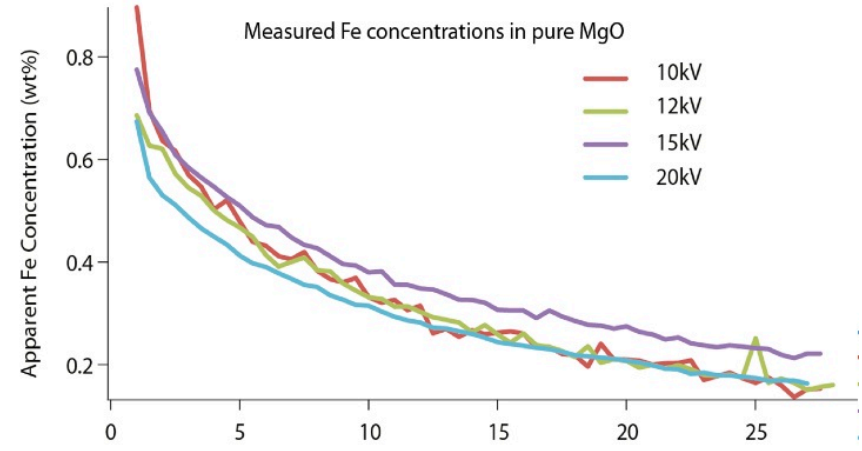

A

Distance from MgO: Fe interface $(\mu \mathrm{m})$

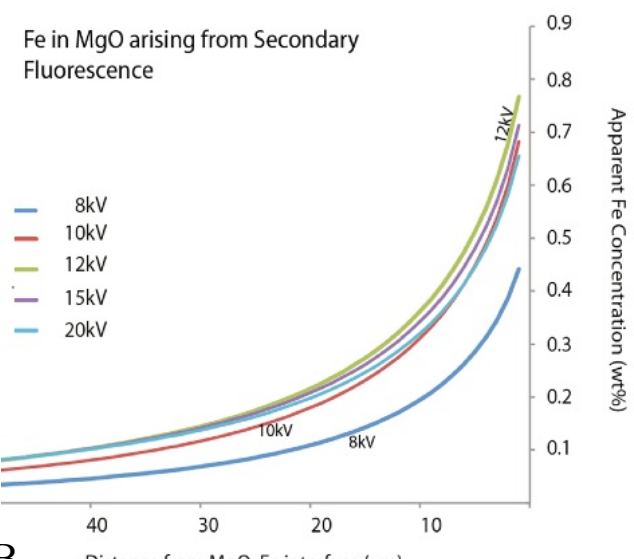

Figure $1 \mathrm{~A}$ ) Measured iron concentrations within magnesiowüstite to 25 microns away from Fe interface at variable accelerating potential. B) Fanal modeled secondary fluorescence effects at varying voltages in a model $\mathrm{MgO}$ - Fe system. 